\title{
LA JUVENTUD JAPONESA ANTE LA CRISIS DEL NEOLIBERALISMO
}

\author{
MICHIKO TANAKA \\ El Colegio de México
}

\section{Introducción}

Con el lema del Partido Liberal Demócrata (PLD), “Porque Japón está en crisis”, Abe Shinzō, su presidente, ganó las elecciones generales a la Cámara de Representantes en diciembre de 2012, y encabezó el gobierno por segunda ocasión. ${ }^{1}$ En efecto, Japón está en una profunda crisis, pero ¿̇cuál es la naturaleza de esta crisis?2 El primer objetivo del presente trabajo es analizar esta crisis enfocándose en uno de los problemas más sensibles del Japón de hoy, la pobreza juvenil. Es cierto que Japón no es el único país que vive este problema y que entre los países de la Organización para la Cooperación y el Desarrollo Económicos muchos padecen una situación más grave; ${ }^{3}$ sin embargo, en 2011, la tasa de empleo de los recién egresados de la universidad fue de $9.1 \%$, récord mínimo desde 1996 cuando se inició el registro. ${ }^{4}$ Es notorio el deterioro de la condición de empleo de los jóvenes a partir de 1993, año en que estalló la burbu-

Este artículo fue recibido por la dirección de la revista el 30 de julio de 2014 y aceptado para su publicación el 19 de enero de 2015.

${ }^{1}$ Abe Shinzō encabezó el gabinete por primera vez del 27 de septiembre de 2006 al 26 de agosto de 2007.

${ }^{2}$ Para Abe Shinzō y el PLD, la crisis es producto de la ineptitud del Partido Demócrata que gobernó Japón de septiembre de 2009 hasta diciembre de 2012 con tres primeros ministros sucesivos: Hatoyama Yukio, Kan Naoto y Noda Yoshihiko. El mensaje del lema es que los políticos del PLD sí saben gobernar.

${ }^{3}$ Según datos de la Organización para la Cooperación y el Desarrollo Económicos, citados por la Oficina del Primer Ministro, en 2009, la tasa de desempleo de jóvenes de entre 15 y 24 años en Japón fue de 9.1\%, mientras que en Francia fue de $22.8 \%$, en Inglaterra de $18.9 \%$, en Estados Unidos de $17.6 \%$, y en Alemania de $11 \%$. Oficina del Primer Ministro, Jyakunen koyōwo torimaku genjō to mondai [Situación y problemas del empleo juvenil], 19 de marzo de 2012, anexo 1.

${ }^{4}$ Ibid., anexo 2 . 
GRÁFICA 1. Cambios en la pirámide de población, 1960-2060
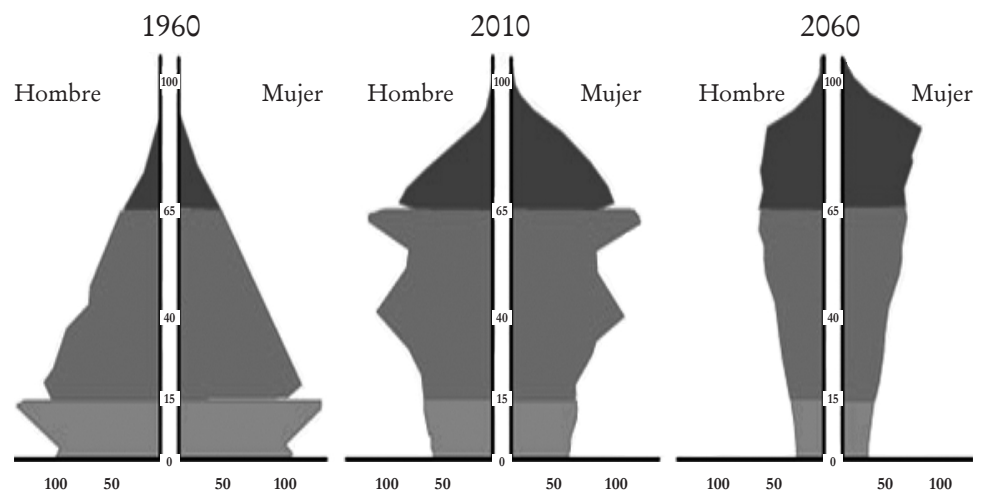

Fuente: Censos nacionales de 1960 y 2010 de la Oficina del Primer Ministro, y estimación para 2060 según estudios del Instituto de Demografía y Seguridad Social.

ja especulativa; la precariedad del empleo y, sobre todo, la falta de perspectiva son fuente de una seria preocupación. Dada la importante diferencia en los salarios entre los empleados regulares y los irregulares, y la poca movilidad laboral una vez iniciada la carrera profesional, la existencia de más de un tercio de la generación juvenil (menos de 35 años) con empleo irregular pronostica no sólo la persistencia de la población de bajo ingreso con poca o nula aportación al sistema tributario por concepto del impuesto sobre la renta y al sistema de la seguridad social, sino también el aumento futuro de la demanda de asistencia pública. Es una seria amenaza para el futuro del país, cuya población envejece (véase gráfica 1).

El segundo objetivo de este trabajo es ver la respuesta de los jóvenes ante la crisis y caracterizar la cultura política de la "generación perdida" mediante el análisis de su actuación como ciudadanos y su cultura cívica, y no únicamente su participación política o su conducta electoral.

Aunque el triple desastre del 11 de marzo de 2011 destacó la situación crítica de Japón, la crisis por sí misma tiene su origen décadas atrás y causas tanto nacionales como internacionales. Para explicar el resurgimiento de la pobreza en Japón —en 
particular de los jóvenes- es necesario reseñar brevemente el contexto histórico de las últimas décadas, a partir del gobierno del primer ministro Nakasone Yasuhiro (noviembre de 1982-junio de 1987), el periodo en que se implantó la política neoliberal.

La pobreza económica juvenil no es el resultado de la falta del esfuerzo individual o de la mala suerte personal, sino producto de una política premeditada y los consecuentes cambios estructurales. Por ello, examinaré algunas medidas clave que condujeron al surgimiento de la "generación perdida". Al abordar el tema me enfocaré en las políticas públicas adoptadas por el gobierno del PLD, solo o en alianza con uno u otro partido, para promover la política neoliberal; sin embargo, haré hincapié en que estas políticas se llevaron a cabo en respuesta a los cambios radicales, tanto en la política internacional -la caída del sistema socialista mundial- como en la sociedad humana en general, que transita hacia la integración global debido a la migración masiva y la comunicación electrónica. Japón, a pesar de su política migratoria tradicionalmente restrictiva, no puede estar fuera de este proceso.

\section{Medidas políticas y empresariales que contribuyeron a la pobreza juvenil}

El periodo neoliberal, comprendido entre el inicio del gobierno de Nakasone Yasuhiro en noviembre de 1982 y la actualidad, se puede dividir en tres etapas:

1. Noviembre de 1982-agosto de 1993: de la formación del gobierno de Nakasone a la renuncia del primer ministro Miyazawa Kiichi.

2. Agosto de 1993-abril de 2001: de la formación del gobierno de coalición de Hosokawa Morihiro a la renuncia del primer ministro Mori Yoshirō.

3. Abril de 2001-diciembre de 2012: de la formación del gobierno de Koizumi Jun'ichirō al retorno al poder de Abe Shinzō. 
A continuación, destacaré algunas medidas que contribuyeron a la reaparición de la pobreza y la formación del "precariado" juvenil. ${ }^{5}$

La primera etapa corresponde al periodo de formación, adolescencia y temprana juventud de la generación que nos ocupa. Comenzó bajo el fuerte liderazgo del primer ministro Nakasone, quien aplicó una serie de medidas encaminadas hacia la apertura económica y el aumento de la competitividad en el mercado internacional. Para entonces, Japón había alcanzado un alto nivel de ingreso per cápita, y el nivel de vida de la población había mejorado sustancialmente al punto de crear el mito del "país de la clase media"; esto, sin embargo, significó el aumento de los salarios y costos de producción. Los industriales japoneses demandaban bajar el costo de la mano de obra mediante la importación de alimentos e insumos baratos. Estados Unidos y algunos países industrializados de Europa, por su parte, presionaban para que se liberalizara el mercado japonés como una medida compensatoria a la agresiva introducción de productos manufacturados de alta calidad y bajo precio japoneses. Para responder a estas exigencias y a la campaña mediática del Japan bashing (apaleo a Japón), Nakasone adoptó como pilares de su política la liberalización del mercado de bienes y capital, la privatización de empresas estatales y la reforma administrativa.

El mecanismo más efectivo para contrarrestar el avance japonés, sin embargo, fue la firma del Acuerdo de Plaza, en 1985, que estableció un valor artificialmente alto del yen como medida de contención a las exportaciones japonesas. En consecuencia, las empresas japonesas que no soportaran el alto costo de producción dentro del país tendrían que trasladar su planta productiva al extranjero, a países vecinos de Asia donde se conseguía mano de obra barata, o a los mismos países importadores, como Estados Unidos y algunos de Europa. Avanzó la internacionalización del capital japonés. La reestructuración industrial que resultó como consecuencia produjo despidos

${ }^{5}$ Precariado es un neologismo compuesto por el término precario, que alude a las condiciones precarias de empleo y vida (hoy, de un tercio de los jóvenes trabajadores menores de 35 años), y proletariado, clásico término marxista que indica la clase desposeída de medios de producción. 
masivos de trabajadores, mayoritariamente adultos mayores, quienes se consideraban poco aptos para acoplarse a la nueva tecnología informática. No obstante, la tasa de desempleo absoluto se mantuvo entre $2.1 \%$ y $2.6 \%$, la más baja entre los países de la Organización para la Cooperación y el Desarrollo Económicos en esta etapa. ${ }^{6} \mathrm{El}$ apoyo gubernamental para promover la reestructuración industrial bajo el efecto de la revolución informática y el subsidio al sector agropecuario afectado por la política de liberalización se cubrían por la emisión de bonos del Estado, lo que implicaba un nuevo problema de deuda pública interna acumulada. ${ }^{7}$

El alza del yen que derivó del Acuerdo de Plaza de 1985 provocó un falso auge económico por la sobrevaloración de las acciones y los bienes raíces japoneses. Con el yen sobrevaluado en el bolsillo, los empresarios y los turistas japoneses rompieron el récord de viajes al extranjero año tras año. Se produjo el fenómeno de rechazo del empleo —conocido como $3 \mathrm{k}$ : kiken, peligroso; kitsui, pesado; kitanai, sucio- de los japoneses, lo que dejó espacio a los trabajadores extranjeros, algunos indocumentados, atraídos por el yen sobrevaluado.

Otro motor de la reestructuración económica fue la privatización de las empresas estatales, como los Ferrocarriles $\mathrm{Na}$ cionales, lo cual, junto con un mayor control administrativo sobre el magisterio y la burocracia, asestó un fuerte golpe al movimiento sindical de la izquierda, porque los trabajadores del sector público eran su base. Esto a su vez debilitó a los partidos de la izquierda socialista y la política social en general retrocedió. Disminuyó la capacidad negociadora de los trabajadores en su conjunto, y la nueva central sindical, la Federación General de Sindicatos de Trabajadores, Rengō, que se constituyó en 1989 para unificar todas las tendencias sindicales ante la ofensiva empresarial y gubernamental, adoptó una postura defensiva y conservadora de los intereses adquiridos. Así, se debilitó la sociedad civil organizada. La prolongada permanencia del PLD en el poder produjo corrupción y contubernio entre los altos fun-

${ }^{6}$ Kanda Fumihito, Shōwa Heizei gendaishi nenpyō [Cronología de las eras Shōwa y Heisei. Del 25 de diciembre de 1926 al 31 de diciembre de 2005], Tokio, Shōgakkan, 2005, p. 163.

${ }^{7}$ Ibid., p. 147. 
cionarios, líderes de fracciones del PLD y empresarios en busca de ventajas en la cambiante situación económica.

La juventud que se formó en la época de abundancia, con buena educación -algunos con experiencia de viajes o estudios en el extranjero-, rechazaba una vida consagrada sólo al trabajo, a la empresa, aunque fuese de prestigio. Buscaban un trabajo que pudiera combinarse con lo que les gustaba hacer en la vida $y$, si no, trabajar lo necesario como freeters ${ }^{8}$ a fin de ganar dinero para su actividad preferida, y quedarse en el hogar paterno sin pretender llevar una vida independiente. No les interesaba la política, que consideraban corrupta, ni la militancia partidaria de la oposición. El conservacionismo ambiental y la búsqueda de la identidad son las dos claves que caracterizan a los jóvenes de esa época. El falso auge económico y la abundante oferta de trabajos temporales bien pagados en yenes parecía ofrecerles la posibilidad de llevar una vida como freeters.

A partir de 1991 comienzan a aparecer síntomas del estallido de la burbuja especulativa y, en octubre de 1992, el Ministerio de Finanzas anuncia que las deudas acumuladas de 21 bancos habían alcanzado los 12300000 yenes. En medio de las quiebras de bancos y otras instituciones financieras, el caso de Sagawakyūbin, que involucró a varios políticos —entre otros, a Kanamaru Shin, vicepresidente del PLD, quien reconoció haber recibido 500 millones de yenes de la empresa-, sirvió como detonante para acelerar las reformas políticas y, como consecuencia, para la derrota electoral del PLD y para los cambios en el gobierno de 1993. La tasa de crecimiento económico registró una estrepitosa caída, como se ve en la gráfica 2.

La segunda etapa se inicia cuando la generación formada en la época de abundancia termina la universidad, a los 22 o 23 años, o la educación media superior, a los 18 años, y entra a un mercado de trabajo reducido por la depresión económica. Una parte de los jóvenes que no encontró trabajo satisfactorio, continuó sus estudios de posgrado; otros, se convirtieron en freeters en espera de una mejor oportunidad, o simplemente

${ }^{8}$ Neologismo que combina free lance y arubaito. El término japonés arubaito proviene de la palabra Arbeit, que significa "trabajo" en alemán; en japonés indica empleo temporal para jóvenes, especialmente para estudiantes. Véase Kosugi Reiko, Jiyūnodaishō/ Freeter [El precio de la libertad/Freeter], Tokio, Rōdōseisaku Kenkyūkenshūkikō, 2002. 


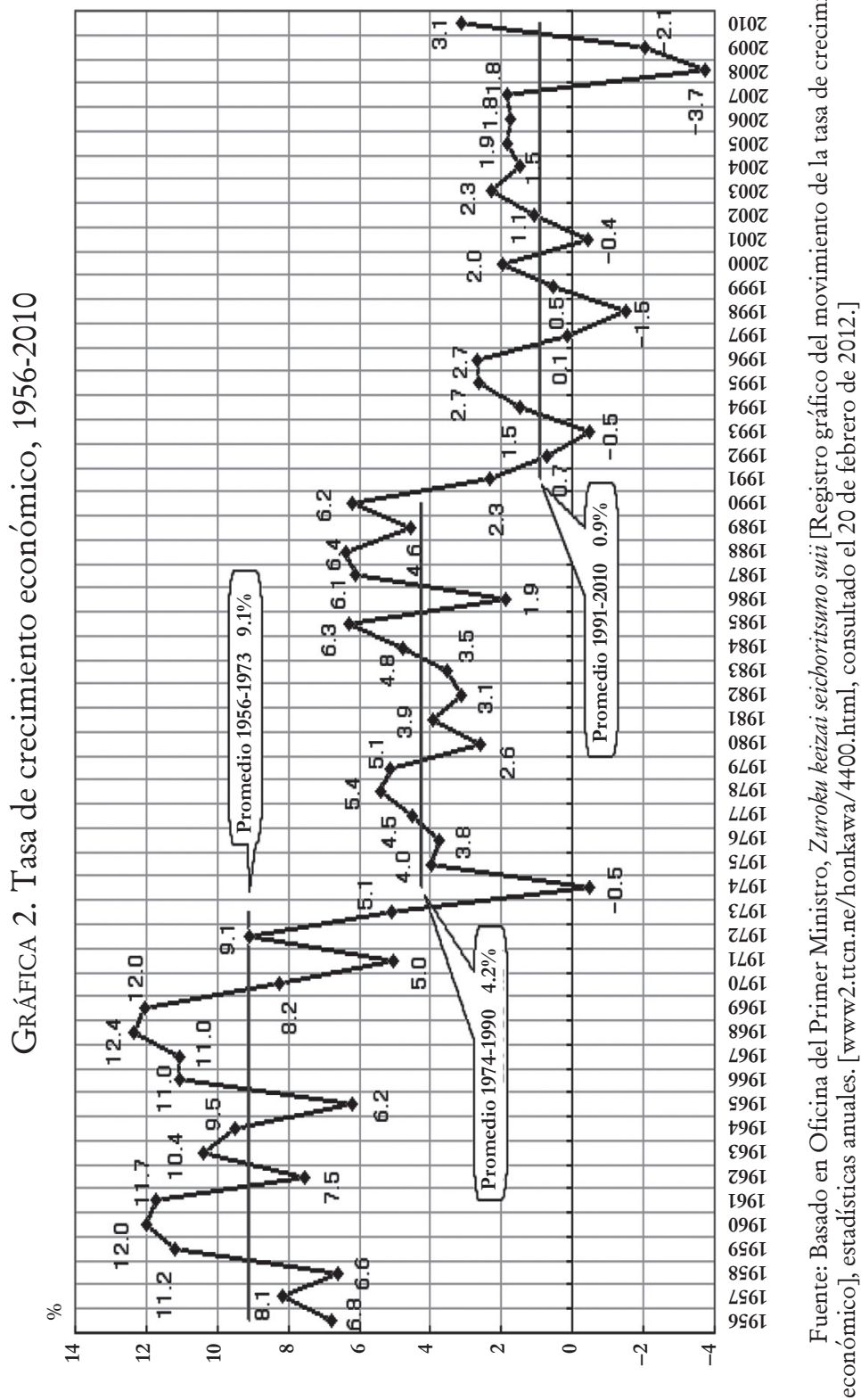


vivían a expensas de los padres, como "ninis". Se esperaba que esta precaria situación del empleo fuera pasajera y que desapareciera con la recuperación económica; no obstante, esto no sucedió y las filas del "precariado" engrosaron cada abril con nuevos egresados por más de veinte años. ${ }^{9}$

En 1993 ocurrió el cambio político y se formó el gobierno de Coalición de seis partidos y dos agrupaciones encabezado por Hosokawa Morihiro del Nuevo Partido de Japón (NPJ)..$^{10}$ Este gobierno, sin embargo, no duró mucho por la diversidad de intereses y porque una buena parte de los dirigentes compartían con los del PLD una cultura política de corrupción y eran vulnerables ante escrutinio judicial. Ozawa Ichirō, uno de los principales actores y promotor del proyecto de convertir Japón en un "país normal" (futsūnokuni), lo que significaba, para él, un país que pudiera enviar tropas al extranjero en una emergencia, ${ }^{11}$ se consideraba seguidor de Tanaka Kakuei, protagonista del sonado caso de soborno por la Compañía Lockheed. El ala izquierdista de la Coalición, Partido Socialista de Japón (PSJ) y otros de inspiración socialista, por su parte, no pudieron proponer un proyecto político alternativo viable, afectados por la caída del sistema socialista mundial. El pequeño partido con base en organizaciones ciudadanas, Partido Vanguardia (PV, Sakigake), exitoso en las políticas locales o prefectorales, no pudo proyectarse en la arena nacional más allá de la figura de su líder Takemura Takeyoshi.

Con una maniobra magistral, el PLD retornó al poder, en 1994, en alianza con el Partido Socialdemócrata de Japón (PSDJ, antes PSJ) al promover a Murayama Tomiichi, entonces presidente del partido, como el primer ministro. Al frente del gobierno, Murayama aceptó la renovación del Tratado de Seguridad Mutua con Estados Unidos y del arriendo de la tierra para sus bases militares en Okinawa, sin hacer caso a la voluntad popular en contra expresada por plebiscito. ${ }^{12}$ Esto causó división en

${ }^{9}$ Cada mejora se cancelaba con nuevas caídas, como la crisis financiera de Asia en 1997, el Lehman shock de 2008 o el triple desastre del 11 de marzo de 2011.

${ }^{10}$ Michiko Tanaka, Cambios políticos en Japón en 1993, México, unam, 1993.

${ }^{11}$ Ichirō Ozawa, Nihon kaizō keikaku [Plan de reordenamiento de Japón], Tokio, Kōdansha, 1993.

${ }^{12}$ Michiko Tanaka (coord.), Política y pensamiento político en Japón, 1926-2012, México, El Colegio de México, 2014, pp. 717-719. 
el PSDJ, de por sí debilitado por la derrota electoral de 1993. El retorno a la dirección del partido de Doi Takako, carismática lideresa que logró el triunfo electoral del PSJ en las elecciones de Cámara de Consejeros en 1989, no pudo evitar su caída definitiva.

En noviembre de 1994, el Yomiuri, el periódico conservador de mayor circulación, publicó un Proyecto de Constitución de Japón con la intención de provocar un amplio debate para reformar la Constitución de $1946 .{ }^{13}$ Como respuesta, resurgió el movimiento por la defensa de la Constitución de paz, encabezado por líderes de opinión, escritores e intelectuales preocupados por un mayor involucramiento de Japón en las guerras de ultramar, que obtuvo apoyo de la generación que conoció la guerra y de la que se benefició por las décadas de desarrollo económico bajo la política pacifista, mas no atrajo a la generación joven.

El gran terremoto de Osaka-Kōbe-Awaji, que ocurrió en enero de 1995, mostró la vulnerabilidad de Japón ante los desastres naturales, a pesar del supuesto avance de la tecnología antisísmica y la desarrollada cultura de prevención de desastres, y produjo dos efectos importantes: demostró la importancia de la Internet como medio de comunicación e hizo surgir acciones ciudadanas voluntarias, en particular entre los jóvenes. Ese mismo año, en marzo, sucedió el ataque indiscriminado a pasajeros y empleados del metro con el mortal gas sarín por los militantes creyentes de la secta Aum. Este incidente incrementó la sensación de vulnerabilidad e indefensión entre los habitantes de las grandes ciudades. ${ }^{14}$ Cuando el gobierno aplicó la Ley de Prevención de Acción Antisocial (Habōhō) para perseguir a los dirigentes de la secta, tanto los medios de comunicación masiva como la mayoría de la ciudadanía lo aplaudieron.

En el mismo año surgió un movimiento neonacionalista que se propuso revisar la historia de Japón con el propósito de reivindicar a los héroes y los episodios relegados por los autores deformados por la democracia de posguerra; demandaba que los japoneses asumieran la responsabilidad de defender a su

${ }^{14}$ Ibid., p. 795. 
país con sus propias manos. La acción más efectiva de este movimiento se atribuye a Kobayashi Yoshinori, quien influyó sobre un importante número de jóvenes a través de caricaturas políticas que desafiaban a las autoridades, la moral, los usos y costumbres convencionales y, sobre todo, a los intelectuales progresistas y defensores de la paz. ${ }^{15}$

En mayo de 1995, la Federación Japonesa de Organizaciones Patronales publicó un documento a fin de formular su postura para salir de la depresión económica que ya llevaba varios años: "Administración japonesa" para una nueva era. Hacia dónde dirigirse y qué medidas deben ser adoptadas. ${ }^{16}$ Destacó en él la necesidad de ajustar la mano de obra según tres tipos de empleos: i) empleo de carrera permanente, para lo cual la capacitación se llevaría a cabo dentro y fuera de la empresa; ii) empleo que requiere especialización con contrato directo de tiempo delimitado, para lo cual la capacitación se llevaría a cabo fuera de la empresa, y iii) empleo flexible o de tiempo parcial, para lo cual habría la capacitación necesaria para la tarea concreta. Conforme a esa necesidad debían reorientarse las políticas laboral y educativa. Ésta y otras sugerencias empresariales pronto surtieron efecto: primero, en la década de 1990, se accionó la llamada "educación con holgura" (yutori kyōiku), que redujo las horas de clase para disminuir la carga escolar y dar tiempo libre a los niños y los jóvenes a fin de que desarrollaran aptitudes personales; sin embargo, esto estimuló la diferenciación social por mérito académico, porque los hogares complementaban la formación de sus hijos con clases extraescolares y actividades formativas pagadas.

Para mediados de la primera década del siglo XXI se abandonó esta política por la baja generalizada del nivel académico de

${ }^{15}$ En su Teoría de la guerra, Kobayashi Yoshinori (Sensōron, Tokio, Gentōsha, 1998) presentó de manera llana y clara la tesis de la agrupación: un país independiente debe armarse para su defensa ya que la guerra es uno de los instrumentos de la política de un Estado soberano. Japón expandió su territorio en detrimento de los países vecinos, pero hacían lo mismo Estados Unidos y las potencias europeas. Japón, en realidad, contribuyó a que los demás pueblos de Asia tomaran conciencia de que puede lucharse contra los occidentales y facilitó su liberación. El culto al emperador, tennō, y la idea de una nación-familia es un mito o un discurso creado que fue necesario para la integración del país como un Estado-nación, como sucedió en todas partes. Véase Tanaka (coord.), Política y pensamiento político en Japón, op. cit., pp. 811-833.

${ }^{16}$ Ibid., pp. 754-767. 
los escolares, y la reforma se dirigió más bien hacia la diferenciación curricular dentro del sistema escolar. Esto respondía a la sugerencia formulada por la Federación de Organizaciones Económicas (Keidanren), en abril de 2004, en la Propuesta para la formación de la generación que debe sobrevivir el siglo XXI. Promover más reformas con base en la "pluralidad", la "competencia" y la "evaluación". ${ }^{17}$ La idea era establecer un mayor control administrativo para impulsar la competencia en todos los niveles: entre los escolares, los docentes y los administrativos, y entre las escuelas, con el propósito de seleccionar a los cuadros de excelencia que pudieran sostener la competitividad japonesa en el mercado mundial de productos de alto valor agregado. Comenzaron a circular términos como kachigumi (los vencedores) y makegumi (los vencidos). Los freeters y los "ninis" que no se colocaron a tiempo en un empleo regular, voluntaria o involuntariamente engrosarían las filas de un tercio de los trabajadores temporales con condiciones inestables y precarias, dadas las reformas laborales que estimularon la aparición del "precariado".

Por la exigencia del sector empresarial también se llevaron a cabo una serie de reformas laborales referentes a los trabajadores temporales. El empleo de trabajadores enviados por agencias de recursos humanos (baken) se reglamentó por primera vez en 1985 para trabajadores especializados, como traductores, secretarios bilingües, taquígrafos bilingües y otros, cuando las empresas extranjeras comenzaron a establecer sus oficinas en Japón. Existía una lista (lista positiva) de actividades aplicables a este tipo de empleo. Bajo la presión empresarial, la lista se extendió poco a poco y, en 1999, se liberalizó, excepto en las industrias manufactureras y actividades señaladas en otra lista (lista negativa); ${ }^{18}$ en 2003 se liberalizó también en las industrias manufactureras y se conservó la restricción sólo para algunas ac-

${ }^{17}$ Este documento refleja la profunda preocupación empresarial sobre el futuro de Japón desde su punto de vista, su sentido de crisis. Por ejemplo, el documento dice: "Hay temor de que, en un futuro cercano, se incremente la juventud carente de la capacidad básica para sostener la vida diaria en la sociedad, se desmorone la fuerza humana que ha soportado nuestra economía y sociedad, y se tambalee el pilar del Estado”. Keizai Dantai Rengōkai, Propuesta para la formación de la generación que debe sobrevivir el siglo XXI. Promover más reformas con base en la "pluralidad", la "competencia" y la "evaluación", Tokio, Keizai Dantai Rengōkai, abril de 2004.

18 Tanaka (coord.), Política y pensamiento político en Japón, op. cit., pp. 767-778. 
tividades señaladas en la lista negativa. Esto dio un gran auge a las empresas proveedoras de recursos humanos, a la vez que proliferaron los empleos en condiciones precarias, especialmente para los jóvenes de la "generación perdida" ${ }^{19}$ Así, se profundizó y se extendió la política neoliberal.

A pesar de la prolongada depresión económica, favorecida por el nuevo sistema electoral de distritos de un solo escaño, el PLD permaneció en el poder, cambió de aliado y se coligó con el Partido de Gobierno Limpio (PGL). A ello fueron favorables también el nuevo orden mundial de monopolaridad estadounidense y la carencia de fuerzas alternativas. Esta inmovilidad alejaba a la juventud de la política y el abstencionismo electoral aumentaba, incluso en las elecciones nacionales.

Desde su fundación, en 1989, la Federación General de Sindicatos se pronunciaba por la reorganización de los partidos y los grupos de oposición; sin embargo, esto tomó su tiempo y apenas en 1996 se fundó el Partido Demócrata (PD) por 57 diputados provenientes de tres partidos de la oposición: PSDJ, Nuevo Partido Progresista (NPS, Sinshintō) y PV, pero pasó más de una década antes de que aglutinara a su alrededor a partidos menores o miembros de otros partidos que pudieran conformar una fuerza política viable para la toma del poder.

La tercera etapa se inicia en abril de 2001 con la llegada al poder de Koizumi Jun'ichirō, quien inauguró un nuevo estilo de hacer política apoyado fuertemente en los medios de comunicación, con imágenes y palabras clichés. Esta política de espectáculo (gekijoseiji 劇場政治), conocida también en otros países, ${ }^{20}$ tuvo gran éxito en Japón, incluso entre los jóvenes, por producir la imagen de un fuerte liderazgo personal. La privatización de los Servicios Postales era su lema, y cuando Koizumi se impuso sobre la resistencia interna del PLD y excluyó a quienes se oponían a la iniciativa de la lista de candidatos oficiales para las elecciones generales de 2001 convocadas a propósito, la opinión pública le aplaudió, y favoreció con sus votos a 60 candidatos jóvenes, novatos en la política nacional, promovidos por Koizumi (Koizumi children o cachorros de Koizumi).

${ }^{19}$ Kosugi Reiko, "Youth Employment in Japan's Economic Recovery: 'Freeters' and 'NEETs', Japan Focus: The Asia Pacific Journal, 11 de mayo de 2009.

${ }^{20}$ Katō Tetsurō, Jōhōsen no jidai. Internet to gekijōseiji, Tokio, Kadensha, 2007. 
A pocos meses de formar su gabinete, ocurrió el múltiple ataque a las Torres Gemelas de Nueva York y al Pentágono, en Washington. La reacción de Koizumi fue inmediata y ofreció la colaboración japonesa a Bush. Se adoptó a todo vapor una legislación especial a fin de permitir el envío de la Fuerza de Autodefensa para la operación logística en el océano Índico durante las guerras de Afganistán e Iraq, que el gobierno de Bush inició unilateralmente, sin la sanción de la ONU; Japón envió sus tropas como parte de la Fuerza de Mantenimiento de la Paz para operaciones de apoyo, sin autorización de entrar en combate. Estos actos ensancharon el desfase entre el preámbulo y el artículo 9 de la Constitución de 1946, que prohíben la guerra como medio de solución de un conflicto internacional, por una parte, y las acciones militares, tal como las emprendidas por el país, por otra. Los gobiernos del PLD trataron de resolver este desfase mediante la flexibilización de la interpretación del preámbulo y del artículo 9 constitucional; al mismo tiempo, preparaban el terreno para la reforma constitucional. En particular, el primer ministro, Abe Shinzō (septiembre de 2006-septiembre de 2007), intentó acelerarla con una legislación forzada a través del procedimiento de plebiscito, a principios de 2007. La derrota del PLD en las elecciones de Cámara de Consejeros, de julio de 2007, y la debilidad y la impopularidad de los gabinetes encabezados por Fukuda Yasuo y Assō Tarō no permitieron seguir con el plan. Aun después del retiro de Abe, la campaña en defensa del artículo 9 continuó hasta la celebración del Foro Internacional sobre el Artículo 9, que se llevó a cabo en mayo de 2008, en Makuhari Messe, espacio para megactividades en el suburbio de Tokio, donde participaron numerosos jóvenes y delegados extranjeros, entre ellos varios premios Nobel de la Paz. ${ }^{21}$

En 2008 ocurrieron dos importantes cambios en el ámbito internacional: el estallido de la crisis económica provocada por la especulación financiera estadounidense (Lehman shock), y el

${ }^{21}$ Hubo una gran concentración de personas: japoneses y extranjeros, notoriedades y masas de gente, políticos, religiosos, artistas y activistas de toda índole. Convocado por iniciativa de Peace Boat, que representa el movimiento pacifista de la década de 1970, y decenas de organizaciones sociales, el Foro tuvo repercusión por Internet, a pesar de que los medios de comunicación masiva no dieron la debida cobertura. 
triunfo electoral de Barak Obama como el primer presidente afroamericano de Estados Unidos. Sin duda, estas circunstancias afectaron la popularidad de PLD y contribuyeron al contundente triunfo del PD en las elecciones generales del 30 de agosto de 2009.

En medio de la crisis económica, luego de la ya añeja depresión económica, la industria militar nacional y el comercio internacional de armamentos constituyen un importante grupo de interés en pro del desarrollo militar. En las recomendaciones al PLD y al PD para efectos de las elecciones generales de 2009, Mitarai Fujio, presidente de la Federación de Organizaciones Económicas, Keidanren, nuevamente insistió en incluir en la agenda política la enmienda del artículo 9 constitucional. El PLD siempre ha tenido una postura favorable a la reforma constitucional, mientras que el PD no tiene una postura unificada interna y se limitó a prometer organizar un amplio debate sobre la Constitución.

Al triunfar con amplia mayoría, sin embargo, el PD prefirió diferir el debate sobre la reforma constitucional para dar prioridad a los asuntos económicos de emergencia y a los puntos anunciados en el Manifiesto electoral. La primera de las prioridades fue la atención a las demandas sociales. En octubre de 2009, el gobierno japonés dio a conocer públicamente, por primera vez, la tasa de pobreza relativa de 1997 a 2006 en Japón y su tendencia creciente (véase gráfica 3). Así, se adoptaron medidas para aminorar las condiciones precarias de empleo para las mujeres, los jóvenes, los trabajadores temporales y de obras determinadas, y se lanzó la iniciativa de reforma para modificar la ley sobre trabajadores baken.

La segunda prioridad del PD fue la política ambiental y la iniciativa japonesa para disminuir la emisión del bióxido de carbono anunciada en el discurso del primer ministro, Hatoyama Yukio, en la Asamblea General de la ONU, en diciembre de 2009; sin embargo, estaba basada en la política de promoción de la energía nuclear "limpia". 22

${ }^{22}$ El The Nerw York Times publicó un artículo de Hatoyama Yukio en agosto de 2009 , donde éste planteó su postura proactiva en materia ambiental. Hatoyama Yukio, “A New Path for Japan”, The New York Times, 26 de agosto de 2009. 
GráfICA 3. Dinámica de la tasa de pobreza relativa

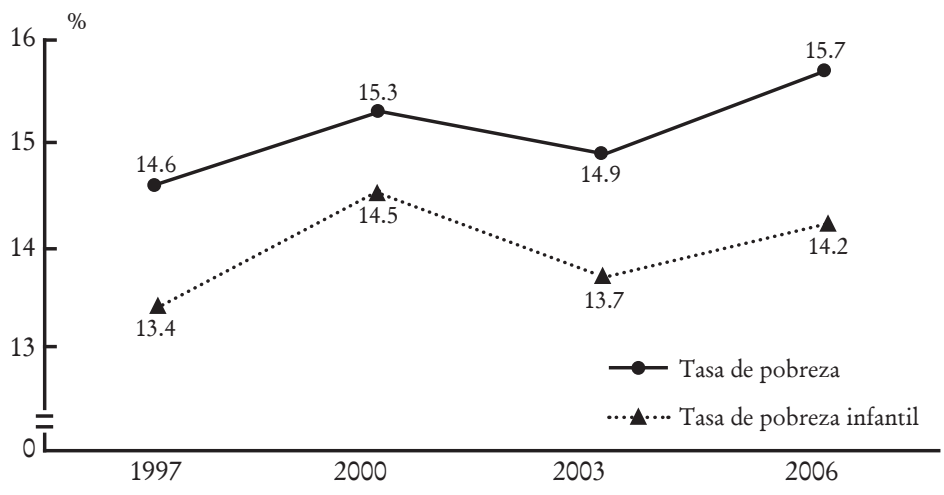

Año estudiado

Fuente: Kōseishō [Ministerio de Salud y Asistencia Pública], "Sōtaiteki hinkonritsu" [Tasa de pobreza relativa], octubre de 2009.

La tercera prioridad fue revertir la tendencia de decrecimiento poblacional mediante subsidios a los hogares con hijos menores, sin importar el estatus económico del hogar. Esta medida fue criticada por la oposición, especialmente por el PLD, por su aplicación universal que implicaba un derrame económico considerable.

El gran terremoto del este de Japón, del 11 de marzo de 2011, cambió drásticamente la agenda política del país; se hizo claro que la sociedad altamente tecnificada es tan vulnerable como las demás ante los desastres naturales, y quizá más si se agrega el riesgo nuclear, como ocurrió en la planta nucleoeléctrica número uno de Fukushima. Irónicamente, el desastre combinado prolongó la vida en el gabinete del primer ministro, Kan Naoto, quien estaba en pugna con la corriente neoliberal dentro del PD y tomó una decisión histórica al solicitar, en mayo de 2011, la suspensión de la operación de la central nucleoeléctrica de Hamaoka, ubicada en una franja altamente vulnerable, ante el esperado gran terremoto de la costa del Pacífico. ${ }^{23}$ La destrucción y el caos abrieron brecha en una es-

${ }^{23}$ Tanaka (coord.), Política y pensamiento político en Japón, op. cit., pp. 847-848. 
tructura aparentemente inamovible como la política de energía nuclear, y hubo propuestas renovadoras para la reconstrucción del país; ${ }^{24}$ sin embargo, poco a poco se restableció el orden y los grupos de interés retomaron el control. El gabinete del primer ministro, Noda Yoshihiko, formado en septiembre de 2011, se comprometió a retomar la política de energía nuclear y a forzar la reapertura de operaciones de los reactores 3 y 4 de la planta nucleoeléctrica de $\overline{\mathrm{O}} \mathrm{i}$, antes de la aprobación de la nueva norma de operación para las centrales nucleoeléctricas $\mathrm{y}$ antes de la constitución de una nueva autoridad para el control de la seguridad nuclear. La propuesta "verde" inicial del $\mathrm{PD}$, de desnuclearizar el país para 2030, tuvo gran aceptación ciudadana; sin embargo, encontró el rechazo total del sector empresarial, lo cual hizo prevalecer en el gobierno la postura promotora de la energía nuclear de Noda y su equipo.

La población, preocupada por su estabilidad económica cotidiana, optó por el retorno del PLD al poder en las elecciones generales de diciembre de 2012, con la esperanza de que se reanimara la economía, promesa que aún está por verse cumplida; mientras tanto, el "Abenomics", la política de desarrollo económico del gabinete de Abe, ha promovido, hasta la fecha, entre otras, la exportación de las plantas nucleoeléctricas al extranjero, como por ejemplo a Vietnam, para compensar por lo pronto la suspensión de obras en Japón; prepara una iniciativa para abolir la prohibición que pesa sobre la exportación de armamentos; asimismo, una campaña personal para obtener la sede de los Juegos Olímpicos de 2020; un aumento del impuesto al valor agregado; una iniciativa para el aumento por el servicio médico gerontológico hasta de $50 \%$ frente al actual 10\%; la suspensión anticipada del impuesto especial empresarial para la reconstrucción y otras medidas que benefician a las grandes empresas transnacionales, pero afectan la economía familiar de la mayoría de la población, en particular, la de los jóvenes y los ya no tan jóvenes en empleo precario.

${ }^{24}$ La estrategia para el renacimiento de Japón, que se dio a conocer el 31 de julio de 2012, fue recibida con aprobación de muchos sectores de la población, porque prometía reconsiderar radicalmente el proyecto nacional poniendo mayor atención a las industrias primarias, la energía renovable y la educación; sin embargo, la postura pro energía nuclear de Noda la dejó de lado. 
GRÁFICA 4A. Estado del empleo irregular entre los jóvenes (hombres)

Empleo irregular según generación

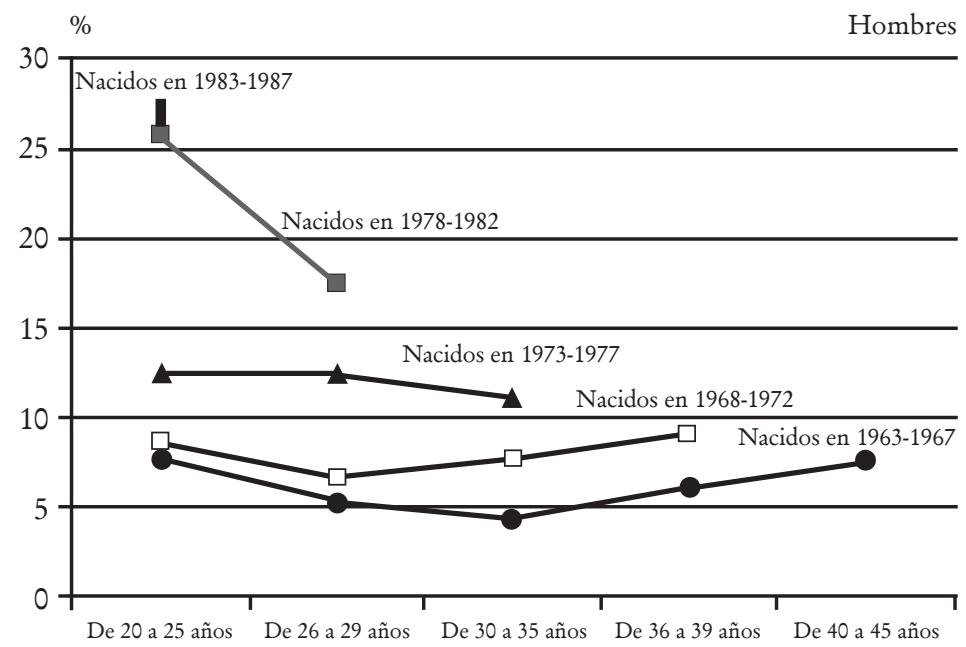

Fuente: Oficina del Primer Ministro, Estudios de diferenciación en empleo de 1982, 1987, 1993, 1998, 2003 y 2008.

Hemos revisado resumidamente cómo se produjo la pobreza juvenil y cómo se instaló un sistema industrial que la incorpora como parte estructural. Como puede verse en las gráficas 4a y 4 b, hoy sigue aumentando la tasa de empleo irregular entre la población joven masculina, y la situación entre las jóvenes mujeres es peor. ${ }^{25} \mathrm{~A}$ continuación veremos quiénes son los jóvenes de hoy y cómo responden a la precariedad laboral, para luego conocer más a fondo su actitud hacia la pobreza y la política pública, y su actividad como ciudadanos a través de un examen del perfil y el pensamiento del activista social Yuasa Makoto.

${ }_{25}$ Oficina del Primer Ministro, Jyakunen koyōwo torimaku genjō to mondai, op. cit., Documento 4-2. 
GRÁFICA 4в. Estado del empleo irregular entre los jóvenes (mujeres)

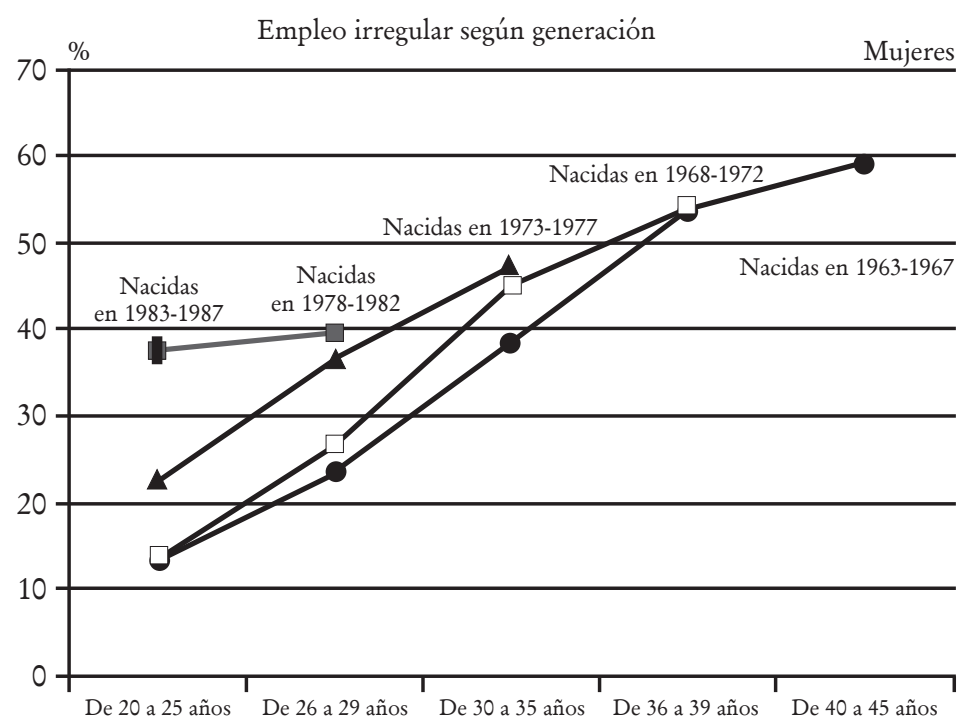

Fuente: Oficina del Primer Ministro, Estudios de diferenciación en empleo de 1982, 1987, 1993, 1998, 2003 y 2008.

\section{La juventud ante la pobreza creciente}

En la década de 1990 y aun entrada la de 2000, la marginalización de un importante número de jóvenes no constituía un problema ni para el gobierno ni para el sector empresarial ni para la sociedad en general. Esto a pesar de la llamada de atención que hacían algunos investigadores, como Tachibanaki Toshiaki, economista de la Universidad de Kioto, sobre la creciente diferenciación económica (keizaikakusa 経済格差) basada en la disparidad patrimonial, como efecto de la burbuja especulativa y la depresión prolongada de la década de 1990.26 La marginalización era tomada como algo "sano" por los polí-

${ }^{26}$ Tachibanaki Toshiaki, Nibonnno keizaikakusa [Diferenciación económica en Japón], Tokio, Iwanami, 1998. 
ticos en el poder y por los dirigentes empresariales para crear interés por la competencia.

A partir de mediados de 2006, reportajes televisivos del equipo de investigación especial del noticiero NHK llamaron la atención pública sobre la existencia de jóvenes en extrema pobreza, quienes viven al día y duermen en sillas de cafés Internet. Según el reportaje de la serie "Generación Perdida", Rosuto zenerēshon, del periódico Asabi, en 2007, casi un tercio de los jóvenes de entre 20 y 35 años no tenían empleo estable. ${ }^{27} \mathrm{El}$ desempleo de los jóvenes es también resultado de la falta de oferta de empleo de calidad; es la generación perdida por haber perdido la oportunidad, en su momento, de ingresar a un empleo de carrera por falta de oferta, pero también por haber tenido una expectativa mayor para un empleo digno, por su educación y experiencia vital como niños y adolescentes.

A partir de la década de 1990, la política neoliberal del gobierno del PLD promovió la reducción de gastos en la educación pública básica. Esto produjo la diferenciación cada vez mayor entre las escuelas, y la escolaridad y la calidad de la educación llegaron a asociarse cada vez más con el nivel económico de los padres y su escolaridad. Se hicieron visibles niños o jóvenes que no querían asistir a la escuela, conocidos como hikikomori, por ser hostigados por los compañeros, bullying (ijime), o simplemente por no tener interés en estudiar por comprender que los esfuerzos que hicieran no les servirían de nada en su futuro pues no se abriría una mejor perspectiva que el entorno social en el que vivían. Hay que aclarar que la indiferencia ante los estudios escolarizados ocurrió no sólo entre el sector de menor ingreso y baja escolaridad, aunque así era en la mayoría de los casos; ocurrió también entre los jóvenes que "fracasaban" en el sistema de evaluación unívoca centrado en rendimientos académicos cuantificables y que no toma en cuenta la personalidad y la habilidad en su conjunto. La juventud, clasificada entre los "triunfadores", los "perdedores" y la mayoría que se ubica entre los dos, es conservadora y está muy preocupada por la posibilidad de perder lo que tiene.

${ }^{27}$ Asahi shinbunsha "Rosutozenerēshon" shuzaihan [Equipo de reportaje de la editorial Asahi sobre la generación perdida], Rosutozenerēshon [La generación perdida], Tokio, Asahishinbunsha, 2007. 
Al estallar la burbuja especulativa financiera, en 1992, y al aumentar el desempleo, surgieron los jóvenes conocidos como freeters y "ninis". El fenómeno, tratado al principio como un capricho de jóvenes sostenidos por los padres, quienes les permitían vivir una vida a su antojo, pronto se convirtió en un problema social, económico y político. Fue una respuesta de los jóvenes a la sociedad que los valoraba sólo como mercancía en el mercado de trabajo; fue una variante de hikikomori ante el trabajo. Se resistían a entrar en la esfera de producción social como fuerza de trabajo permanente; algunos tenían una actividad donde lograban cierta autorrealización y trabajaban sólo de tiempo parcial, como freeters o como trabajadores enviados por agencias haken, o vivían de sus padres, quienes les proveían de lo necesario, como fue el caso del activista social Yuasa Makoto, mientras su padre vivía. Otros rechazaban el consumismo y buscaban alternativas al mercado de consumo masivo. Aquí encontramos una gran variedad de colectivos de jóvenes, quienes hablaban, actuaban y demostraban su modo de vivir y consumir con sentido ecológico; promovían la idea de responsabilidad social y el trato justo y solidario en las transacciones comerciales; ${ }^{28}$ otros más trataban de convertirse en productores alternativos. Como reporta el número especial de la revista agrícola Gendai nōgyō: el retorno a la agricultura kinō ya no es una rareza $;^{29}$ hay jóvenes que optan por zafarse del empleo de carrera voluntariamente ${ }^{30} \mathrm{y}$ logran autorrealizarse al dedicarse a esas actividades alternativas.

Sin embargo, la situación de la mayoría de los jóvenes con empleo precario por un tiempo prolongado es desesperante, ya que no hay ninguna salida a la pobreza y la inestabilidad mientras no se modifique el proyecto neoliberal de economía. Reportes en prensa y televisión, que comenzaron a aparecer desde fines de 2006, presentaron la situación de miseria a la

${ }^{28}$ En una avenida sin tránsito vehicular, en el parque Yoyogi, el último domingo de cada mes se establece una feria de productores alternativos de bienes y servicios que ofrece una muestra de las actividades y modus vivendi de este tipo de jóvenes.

${ }^{29}$ Gendai nōgyō [Agricultura contemporánea], número especial: Datsugurobarizeshon [posglobalización], 2007.

${ }^{30}$ Jo Shigeyuki, Sannendeyametawakamonowa dokoeittanoka. Autosaidāno jidai [¿A dónde se fueron los jóvenes que renunciaron al trabajo en los primeros tres años? La época de los outsiders], Tokio, Chikumashobō, 2008. 
cual están reducidos un considerable número de jóvenes: sin domicilio, sin ahorro, sin seguridad social, sin pareja ni perspectiva de formar una familia algún día, sin relaciones sociales con que contar en caso de emergencia. ${ }^{31}$

Ante la falta de una política social y la insensibilidad de la sociedad civil organizada, algunos jóvenes desempleados, o con empleo precario, comenzaron a denunciar a los adultos con recursos y poder, quienes los marginaban y orillaban a la miseria. En enero de 2007, la revista de corta vida Foro de Debate (Ronza) publicó un artículo intitulado "Quisiera abofetear a Maruyama Masao”, de Akagi Tomohiro, freeter de 34 años. ${ }^{32}$ Lo que más llamó la atención del público es que su rebeldía se dirigía no sólo a los gobernantes o los intereses económicos establecidos, sino también a los adultos clasemedieros que tenían una vejez garantizada, a los líderes sindicales que sólo defendían los intereses adquiridos de sus agremiados, y a los intelectuales progresistas que se ocupaban de cualquier otro asunto sin mostrar ninguna sensibilidad por la desesperante situación de los jóvenes marginados. Para ellos, el viejo criterio de la derecha o la izquierda no tiene mucho sentido. Para los freeters, el mensaje más impresionante de Akagi fue que era mejor la guerra que la paz en la que no se abre ninguna oportunidad para ellos. Su situación era tan desesperada que podían arrimarse a las organizaciones ultranacionalistas o cambiarse a las de la izquierda, según su propio beneficio y conveniencia, sin mayor compromiso.

Algunos de estos "perdedores" adoptaban formas irracionales y violentas de rechazo a la sociedad excluyente, como sucedió en el caso de un joven haken de 25 años, quien, un día en junio de 2008, se lanzó con una camioneta rentada contra una multitud en una esquina de Akihabara y causó la muerte de siete personas de entre 19 y 74 años. Es simbólico el hecho de que esto haya sucedido justo en el sitio preferido de la generación

${ }^{31}$ El primer libro que abordó el tema de la pobreza contemporánea en Japón fue escrito por Iwata Masami, Gendai no binkon. Working poor/homeless/seikatsubogo [Pobreza contemporánea. Trabajadores pobres, sin hogar ni asistencia pública], Tokio, Chikumashobō, 2007.

${ }^{32}$ Akagi Tomohiro, "Mruyama Masaono hoppetao hippatakitai” [Quisiera abofetear a Maruyama Masao], Ronza, enero de 2007. 
de cibernautas y otakus, jóvenes ofuscados en busca de su propia identidad. La respuesta del gobierno del PLD, encabezado por el primer ministro Asō Tarō, supuestamente aficionado de la cultura pop y fan de héroes de cómics y animes, fue una nueva reforma educativa para promover los valores morales tradicionales.

El desconocimiento y la incapacidad de comprender la crítica situación de los jóvenes marginados, que caracterizaba a los dirigentes políticos y líderes de organizaciones sociales, hicieron que las medidas para la solución del problema tardaran en adoptarse. Con el cambio de la coalición de partidos en el poder como resultado de las elecciones generales de agosto de 2009, por primera vez se planteó la necesidad de tomarlo en serio.

Mientras tanto, fueron los mismos jóvenes inconformes con el orden social y político, de exclusión, quienes comenzaron a actuar para salvar a los jóvenes en situación de miseria e indefensión. Por ejemplo, Moyai: Centro en pro de una vida autosostenida, surgió en mayo de 2001 por iniciativa de Yuasa Makoto y compañeros ${ }^{33}$ para dar cobijo de emergencia a los indigentes de Tokio, y apoyar a que recuperasen su capacidad de vivir de manera autosuficiente y a que construyesen una red social de comunicación y apoyo mutuo. Junto con otras organizaciones no lucrativas, Moyai estableció el Campamento para Pasar el Año en el céntrico parque público de Hibiya, el fin de año de 2008, para dar un apoyo de emergencia a los trabajadores baken, que no tienen domicilio permanente, ni empleo fijo por ser eventual, de periodo vacacional, ni tienen familiares o amigos a quienes acudir por ayuda (véase imagen 1). En el fin de año de 2009, la tarea de auxilio fue nuevamente coordinada por Yuasa, pero esta vez con apoyo del gobierno y la alcaldía de Tokio.

En sus acciones políticas o cívicas, los jóvenes evitan las formas convencionales de protesta y prefieren introducir elementos lúdicos o espectaculares para atraer la atención mediática

${ }^{33}$ Yuasa Makoto (1969) comenzó a apoyar a los indigentes en 1995, cuando era estudiante de posgrado en la carrera de derecho en la Universidad de Tokio. En 2000 estableció el Banco de alimentos para ofrecer arroz de auxilio a los indigentes. En 2001 fundó Moyai y desde entonces tiene el cargo de secretario ejecutivo sin recibir sueldo alguno. 


\section{IMAGEN 1.}

Aldea de trabajadores haken, el fin de año de 2009

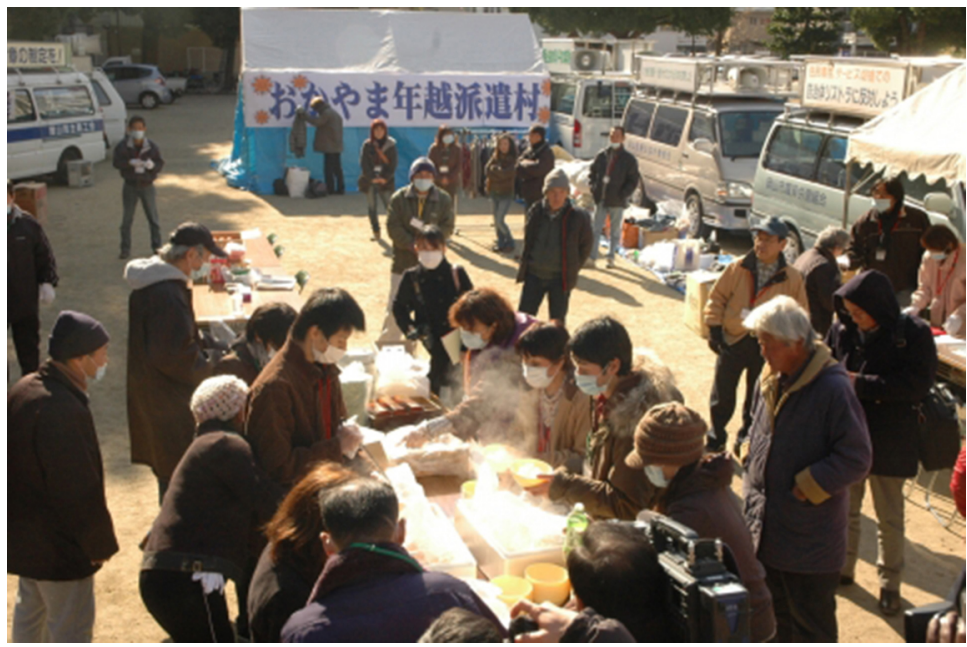

Aldea de trabajadores haken, el fin de año de 2009, en el parque Ōtomo, ciudad de Okayama, del 29 de diciembre de 2009 al 3 de enero de 2010. [asahisosho.or.jp/ report/2009/12, consultado el 22 de septiembre de 2015.]

utilizada para propagar la idea y protegerse de la represión policiaca. Adoptan sin prejuicio las formas novedosas o, inspirándose en la tradición popular, echan mano de lo que sea útil en términos de comunicación, manifestación y solución del problema. Por ejemplo, hay jóvenes desempleados que llevaron a cabo un performance de protesta en invierno, en la transitada plaza semisubterránea el Éxito Occidental de la estación de Shinjuku y en la plaza comercial de moda Roppongi Hills: se instalaron con un calentador de pies cubierto con edredón y una estufa portátil, y cazuelas con alimento, nabe, para "disfrutar" en medio de las miradas de reproche o curiosidad de los transeúntes. ${ }^{34}$

Al salir a la calle también buscan una originalidad que capte la atención. En una manifestación del Día del Trabajo,

${ }^{34}$ Matsumoto Hajime y otro más de Shirōtonoran (Asociación de Rebelión de no Profesionales). 
el 1 de mayo, tres jóvenes dieron aviso a la policía de su Manifestación de Tres Personas. Se efectuó la protesta en medio de numerosos policías, perplejos, que observaban la marcha de, efectivamente, tres manifestantes, cada uno con su pancarta de demandas. ${ }^{35}$ Otro ejemplo fue la llamada Manifestación de Línea India (Indiokeidemo インデイオ系デモ) convocada por medio de redes sociales para celebrar el 1 de mayo de 2010, que llamó la atención de los medios de comunicación a pesar de su reducido número, alrededor de 200 participantes, los cuales llevaban pancartas con demandas individuales, sin ninguna consigna unificada ni coordinación, salvo el punto de reunión, la ruta de recorrido y el punto de disolución. Sobre este acto público de protesta se publicó un fotorreportaje que se difundió en Internet y causó un amplio debate acerca de su naturaleza y efectividad. ${ }^{36}$

Otros jóvenes empobrecidos buscaron combinar la subsistencia con la resistencia a la cultura dominante. Estos jóvenes desempleados establecieron sus boutiques, puestos de artículos de reciclaje, arreglados con gusto, en locales abandonados de una de las calles adyacentes a la estación de Kōenji, otrora lugar clasemediero por excelencia, y combinaron la acción por la necesidad con la de denuncia de la sociedad de consumo y la solidaridad con los pequeños comerciantes sobrevivientes del alguna vez concurrido pasaje comercial que era indicador de la vitalidad de la economía local. ${ }^{37}$ Las pequeñas tiendas son también perdedoras, que sufrieron merma por la competencia desleal de los supermercados y las tiendas de franquicia de grandes cadenas comerciales, ganadoras bajo la política neoliberal.

En cambio, Moyai construye su movimiento sobre la tradición del activismo social de settsurumento (asentamiento), de antes de la Guerra de 15 años (1931-1945), iniciado por Kagawa Toyohiko y seguidores, aunque aquél no adopta el sustento ideológico cristiano. Moyai se refiere a la forma tradicional ru-

${ }^{35}$ En esto participaron algunos de la Asociación de Rebelión de no Profesionales.

${ }^{36}$ Fukumoto Emi et al., "Jiyūto seizonno Mēdē 2010. Demotaiga Shinjukuno hankagaiwo neriaruku” (1 de mayo de 2010. ¡Por la libertad y la vida! La manifestación marcha por las calles comerciales de Shinjuku), comunicado electrónico, Japan Alternative News for Justices and New Cultures Blog, 5 de mayo de 2010.

37 Observación directa en el verano de 2007 de la autora. 
ral de solidaridad, moyai (舫), ayuda recíproca mediante el intercambio de mano de obra. Según Yuasa, entre los jóvenes japoneses se ha arraigado el excesivo sentido de responsabilidad propia como consecuencia de la inculcación de la filosofía neoliberal de valerse por sí mismo, atenerse al resultado de la competencia y no molestar a nadie. Como se declara en el manifiesto de Moyai, la vida autosuficiente no quiere decir no contar con los demás. Moyai ofrece múltiples apoyos a los indigentes, desde el auxilio de emergencia para salvaguarda de la vida, apoyo en la consecución de la asistencia pública, domicilio, empleo, servicio médico y asistencia legal, hasta para la construcción de su red social mediante el desarrollo de la capacidad de socializar y el ofrecimiento de un espacio, una cafetería para ser manejada por ellos mismos. Una función de particular importancia que ofrece Moyai es ser garante para rentar un cuarto, ya que el domicilio fijo es condición sine qua non de empleo e, incluso, para ejercer el derecho ciudadano básico de votar.

Los jóvenes activistas que luchan contra las múltiples marginaciones han hecho su propia lectura de los textos clásicos de movimiento social - por ejemplo, de las obras de Marx-y han creado conceptos como precariado, unión de proletariado y empleo precario. Al tomar conciencia de la necesidad de unirse para defender sus derechos, Natori Manabu, Kawazoe Makoto $^{38}$ y compañeros, asumieron la iniciativa de organizar el sindicato de trabajadores de empleo temporal y baken, la Unión de Trabajadores Jóvenes del Área Metropolitana (Shutoken Seinen Rōdōsha Yunion). ${ }^{39}$ Estas iniciativas, junto con severas críticas por parte de los voceros de los jóvenes de empleo precario, hicieron que las organizaciones sindicales establecidas también comenzaran a fijar su atención en el problema del empleo precario y temporal. ${ }^{40}$

38 Sobre Kawazoe Makoto, véase su twitter @kawazoemakoto; sobre Shutoken Senen Yunion véase el sitio oficial del sindicato: www.seinen-u.org/index.html.

${ }^{39}$ Shutoken Senen Rōdōsha Yunion [Unión de Jóvenes Trabajadores del Área Metropolitana], [www.seinen-u.org/index.html, consultado el 11 de marzo de 2015].

${ }^{40}$ El noticiero de NHK Radio informó, el 14 de febrero de 2010, que por primera vez Zenrō había incluido en la agenda de negociación de la Ofensiva Primaveral de 2010 la mejora de las condiciones laborales de trabajadores irregulares y entablado pláticas con Nihon Jinzai Haken Kyōkai, organización de las empresas de este sector económico. 
Para los jóvenes que participan en el nuevo movimiento social, la Constitución de 1946 tiene valor, ya no sólo por el artículo 9 que prohíbe la guerra como medio de solución de conflictos internacionales, sino además por otros artículos que ofrecen el fundamento para la garantía de la vida y los derechos humanos, y la responsabilidad del gobierno de proporcionar una base mínima, socioeconómica y cultural, indispensable para la dignidad humana. ${ }^{41}$

En el siguiente apartado me enfocaré en Yuasa Makoto y sus actividades como dirigente de Moyai y la Red contra la Pobreza (Hanbinkon nettowāku 反貧困ネットワーク), su actuación como asesor del gabinete de Kan Naoto, del PD, y su reciente nombramiento como profesor de la política de bienestar público en la Universidad de Hōsei, para entender más a fondo una expresión de la cultura política de la juventud de hoy.

\section{Yuasa Makoto o la nueva cultura cívica de "la generación perdida"}

Una de las características de su generación es la habilidad en el uso de los recursos digitales y la comunicación social por Internet. Hay información sobre él en Internet. ${ }^{42}$ Yuasa Makoto nació, en 1969, en Tokio. Su padre era periodista y su madre maestra, quienes le dieron una buena educación hasta llegar a estudios de posgrado. Los contactos con estudiantes voluntarios que visitaban su casa para apoyar en los estudios a su hermano discapacitado lo acercaron al movimiento social de solidaridad. Como muchos de su generación, no quiso ser asalariado, amarrado a una compañía u oficina pública; deseaba trabajar como profesional independiente e ingresó en la Universidad de Tokio, aunque dedicó la mayor parte de su tiempo a actividades como voluntario en apoyo de niños discapacitados o de indigentes en el área de Shibuya. Inició sus estudios de posgrado con la idea de hacer una carrera académica. No dejó sus actividades de voluntariado social. Trabajaba de freeter y complementaba sus

${ }^{41}$ Tanaka (coord.), Política y pensamiento político en Japón, op. cit., pp. 252-265.

${ }^{42}$ Wikipedia (en japonés), "Yuasa, Makoto". 
gastos con el apoyo económico de sus padres, como muchos de sus compañeros del movimiento.

A la muerte de su padre, proveedor principal de la familia, decidió abandonar su aspiración académica y se dedicó de lleno a la causa de los pobres. En 2000 inició un movimiento de banco de alimentos, que recordaría la práctica budista de la limosna (kisha 喜捨) o del almacén comunitario para tiempo de sequía o desastre natural (shasō 社倉), y, en el siguiente año estableció, junto con sus compañeros del movimiento social de apoyo al autosostenimiento de los indigentes, una organización no lucrativa, Moyai. Como secretario ejecutivo voluntario de Moyai, Yuasa promueve la autogestión de las personas en extrema pobreza y defiende sus derechos humanos básicos. En 2002 estableció Asian Workers' Network, que fundaría empresas sociales, como la del reciclaje de ropas usadas mediante las cuales las personas en extrema pobreza, sin nexos sociales, pudieran procurarse modos de ganarse la vida por sí mismos.

A través de sus actividades tomó conciencia del problema estructural de la pobreza actual en Japón. En 2005 publicó un manual para trámites de asistencia pública a fin de facilitar la obtención del subsidio gubernamental a la población en extrema pobreza y para oponerse a la corriente predominante de corte presupuestal y obstaculización a la obtención de la asistencia pública. No era raro el caso de desempleados en extrema necesidad que eran rechazados por los funcionarios al tramitar la solicitud de asistencia pública. Los propios necesitados, frecuentemente, no se animaban a pedirla por considerar indigno recibir la asistencia; por lo tanto, una de las actividades importantes de Moyai es acompañar a las personas en extrema pobreza a realizar el trámite en la oficina pública y abogar por su legítimo derecho. La forma de solicitud se colocó en el sitio web de Moyai, con un contacto de citas para asesoría. Entre los nuevos pobres hay muchos jóvenes que "viven" en cafés Internet, quienes ofrecen servicio de 24 horas. Yuasa es tuitero (twitter.com/yuasamakoto) y se pueden seguir sus actividades y compromisos del momento.

En 2007, al conocer la declaración de Hiranaka Takezō, ministro extraordinario del gabinete de Abe Shinzō, de que en Japón no existía pobreza en sentido estricto, Yuasa hizo su de- 
but en los medios de comunicación con el libro intitulado $L a$ invasión de la pobreza (Hinkonshürai 貧困襲来), ${ }^{43}$ y organizó la Red contra la Pobreza, donde funge como secretario ejecutivo voluntario. En 2008 publicó el libro Antipobreza. Salida de la sociedad resbaladilla (反貧困 すべり台社会からの脱 出), que obtuvo reconocimiento público y varios premios. ${ }^{44}$ Yuasa se convirtió en un líder de opinión que emite críticas al gobierno y advertencias a la sociedad indolente.

Luego de establecerse el gobierno del Partido Demócrata, en septiembre, como resultado de las elecciones generales de fines de agosto de 2009, en octubre, Yuasa empezó a colaborar con el gobierno por invitación de Kan Naoto, entonces ministro de Estrategia y Planeación, en calidad de asesor del gabinete de Hatoyama Yukio. A fin de año se establecieron varias aldeas de trabajadores temporales haken para pasar el año, con apoyo de las autoridades centrales y municipales, que ofrecían atención médica, reubicación en viviendas de asistencia social y orientación a los "aldeanos" para conseguir empleo cuando se clausuraron las aldeas a principios del siguiente año. Yuasa renunció al cargo en febrero, porque consideró que sus tareas habían sido cumplidas. En mayo fue nombrado asesor en la Oficina Central para Medidas de Emergencia en la Creación de Empleo (緊急雇用対策本部); fue en este contexto cuando ocurrió el gran terremoto de Tōhoku, con graves consecuencias económicas y sociales.

Ante la gran tragedia humana y la necesidad de canalizar justa y expeditamente la ayuda, el gobierno del primer ministro Kan Naoto lo nombró coordinador de acciones ciudadanas de solidaridad, apoyo y voluntariado, a través del Consejo Nacional de Asistencia Social (全国社会福祉協議会), al lado de Tsujimoto Kiyomi, miembro de la Dieta sin afiliación partidista. De inmediato, en las redes sociales, como Twitter, circularon comentarios en pro y en contra de este nombramiento. Para algunos, fue una atinada asignación a un hombre de experiencia y voluntad; para otros, un error confundir el movimiento social

${ }^{43}$ Yuasa Makoto, Hinkon shürai. Hinkonwa jikosekininjyanai [Invasión de la pobreza. La pobreza no es responsabilidad de uno mismo], Tokio, Yamabukishoten, 2007.

${ }^{44}$ Yuasa Makoto, Hanbinkon. Suberidaishakaikarano dasshutsu [Contra la pobreza. Escape de la sociedad resbaladilla], Tokio, Iwanamishoten, 2008. 
con la política social del gobierno. Las acciones ciudadanas voluntarias no pueden ni deben ser controladas por el gobierno, aunque sea mediante un activista social como él. Aún es prematuro juzgar este nuevo paso tanto para su vida como para la política pública en Japón; sin embargo, debido a la coordinación de la logística y la información sobre las actividades solidarias de distintas organizaciones no lucrativas y ciudadanos, no hay duda de que él estuvo en una posición de mayor perspectiva para observar el gran movimiento de millones de jóvenes que iban y regresaban como voluntarios en apoyo a la gente en las zonas de desastre, campamentos de refugiados y habitaciones provisionales. ${ }^{45}$ Con el paso del tiempo, la vida retorna a la normalidad, aunque en las zonas afectadas por la radiactividad, el tiempo de refugio y el retorno a la "normalidad" se extienden indefinidamente. La población afectada debe convivir con el temor del potencial efecto de la radiactividad sobre su salud toda la vida. El gobierno prefectoral de Fukushima impuso el monitoreo de por vida de los menores afectados.

Para reconocer el pensamiento y los principios de acción de Yuasa Makoto pueden consultarse sus obras publicadas y las páginas oficiales de las organizaciones en que funge como secretario ejecutivo voluntario, Moyai y la Red contra la Pobreza, ${ }^{46}$ así como Wikipedia en japonés. Yuasa fue uno de los primeros en alertar a la sociedad sobre el crecimiento de la pobreza extrema y acerca del nuevo fenómeno de la pobreza juvenil; analizó sus causas y las sintetizó en cinco enajenaciones (itsutsu no sogai五つの疎外):

- del trabajo

- de la seguridad social

- de la asistencia social pública

- de la familia

- de sí mismo

${ }^{45}$ Yuasa Makoto, "Seismic Disaster and Poverty in Japan: Everyday-life Support to Victims and Community Organization", ponencia presentada en el simposio internacional Desastre de Fukushima y futuro de la energía nuclear, XII Congreso Internacional de la Asociación Latinoamericana de Estudios de Asia y África, Puebla, junio de 2012.

${ }^{46}$ Hanhinkon nettowāku (Red contra la Pobreza). [www.k5.dion.ne.jp/ hinky/, consultado el 18 de octubre de 2014]. 
Es común indicar las cuatro primeras enajenaciones como causas de la pobreza. El desempleo prolongado conduce a la pérdida de la cobertura del seguro social. Las autoridades de todos los niveles tratan de reducir al mínimo a los beneficiarios de la asistencia social y establecen barreras complicadas para calificarse como beneficiario de la ayuda gubernamental. Los pobres y los desempleados tienen menos oportunidades para formar una familia o conseguir una pareja estable. Yuasa señala como quinta enajenación la de sí mismo; según él, la idea de la responsabilidad por uno mismo fue inculcada desde temprana edad tan fuertemente durante la educación escolar y la socialización tanto en el hogar como en la sociedad, y está tan arraigada en la conciencia de cada individuo, que muchos buscan en sí mismos la causa de la pobreza y tratan de resolver el problema por sí solos, por lo que evitan acudir por ayuda. En realidad, la pobreza es estructural y resulta de una opción política deliberada; por ello, la salida individual es limitada. Más bien, cuando alguien cae en la pobreza funciona un mecanismo que lo hunde cada vez más, como veremos en seguida.

Negocio de la pobreza (binkonbizinesu 貧困ビジネス), identificado y nombrado así por Yuasa, es ese mecanismo que la agrava. Surge donde los pobres necesitan remediar las carencias que sufren como consecuencia de las enajenaciones: empleo temporal bajo precarias condiciones laborales; vivienda o alojamiento temporal de baja renta, que no requiere de garantes ni pagos anticipados y que suelen ser muy reducidos y de mala calidad, donde además se lanzan las pertenencias fuera de la habitación en caso de atraso en la renta; préstamos o créditos con altísimo interés y severas condiciones de pago; precaria alimentación y auxilio médico limitado, lo que mina la salud, y otras. Los empresarios dedicados a estos negocios se presentan como benefactores, ya que, según ellos, sin su oferta los pobres se quedarían desamparados. El gobierno del PLD, impulsor de la política neoliberal desde principios de la década de 1980, consideraba que la diferenciación socioeconómica era un buen estímulo para que la gente se esforzase a fin de alcanzar una mejor situación económica $y$, por lo tanto, que no debía gastar demasiado en la política social de asistencia. Los negocios de la pobreza se consideraban una buena solución pa- 
ra cubrir la necesidad de este sector de la población. Yuasa denunció sus prácticas inhumanas y su mecanismo de explotación de los más necesitados.

También explica por qué es difícil para los pobres salir de la pobreza. Comúnmente, cada persona tiene un "colchón amortiguador” contra adversidades, que él llama tamari 溜まり(reserva), que podría ser el ahorro, nexos personales, título o grados académicos o alguna capacidad única. Si la persona en pobreza no cuenta con ninguno de estos elementos; por ejemplo, un desempleado sin patrimonio, talento especial o apoyo familiar y de baja escolaridad, es común que continúe en la pobreza y que con el tiempo su situación socioeconómica se deteriore. La organización no lucrativa Moyai intenta suplir las carencias de los necesitados con un "colchón amortiguador" subrogado mediante asesoría. El propósito de Moyai es ayudar a los pobres a solucionar sus necesidades inmediatas - por ejemplo, obtener asistencia pública-, y a salir por sí mismos de la pobreza. Yuasa y parte del equipo de colaboradores son voluntarios y no reciben remuneración alguna. Los recursos que obtiene se destinan al mantenimiento del local, honorarios del personal, gastos de oficina y asesoría, acompañamiento durante la gestión de asistencia pública, préstamos para el pago inicial de una renta, y otros. Con la colaboración de la misma gente que ha recibido asesoría de Moyai funciona una cafetería Komorebi, como espacio para el establecimiento y el reforzamiento de las relaciones sociales. Con el propósito de apoyar las iniciativas empresariales de la gente - por ejemplo, un negocio de reciclaje de ropa u otros materiales- se estableció una Red de Trabajadores de Asia. Para todas estas actividades se hace amplio uso de la Internet.

Consecuente con su postura en el debate sobre la pobreza en Japón, Yuasa Makoto organizó una Red contra la Pobreza, Hanbinkon nettowāku, y lleva a cabo actividades culturales y musicales, cuya cuota de admisión y ganancias por venta de bebidas y alimentos se destinan a diferentes programas de la red. ${ }^{47}$

${ }^{47}$ En julio de 2011 asistí a un Live Rock and Talk Show en un espacio musical subterráneo en Roppongi, donde conocí personalmente a Yuasa Makoto. Me di cuenta de su cualidad como performancero: sin actuar, su mismo modo de ser, habla y convence; su rostro y figura joven, devoto a la causa de los pobres, se mantienen sin cambio 
Yuasa Makoto afirma que no tiene ningún maestro o ideología particular a la cual se deba su pensamiento o acción. Igual que muchos jóvenes de su generación, no necesita respaldo de algún partido o escuela teórica para formular sus ideas y actuar; tiene gran facilidad para comunicarse socialmente en el ciberespacio, del que hace amplio uso para acciones concretas y efectivas, como se mostró en el caso de las aldeas de trabajadores haken para pasar el año. Su postura ante el gobierno es flexible: colabora con él mientras sirva para avanzar hacia la solución del problema principal de la pobreza y el desempleo. Asumió la tarea de la coordinación de organizaciones voluntarias para el apoyo a los damnificados del tsunami y el accidente nuclear, tarea que dejó cuando Kan fue desplazado y Noda encabezó el gabinete. Veremos qué nuevas ideas e iniciativas puede proponer luego de esta experiencia, ahora como profesor universitario. Estuvo junto con millones de jóvenes que se trasladaron a los poblados azotados por el tsunami para recoger el escombro, y a los centros temporales o habitaciones provisionales para los damnificados a fin de distribuir víveres o entretener a los niños y adultos mayores, jóvenes que mostraron su solidaridad y contribuyeron a la reconstrucción del área de desastre de una manera u otra; que tuvieron acceso a informaciones verídicas, o conocieron alternativas que pueden difundir o analizar y formular sus propias opiniones y posiciones políticas; jóvenes que modificarán el rumbo del país, esperamos, para bien.

desde que aparecieron en Internet hace varios años. No tiene el gesto de importancia que suele adquirirse cuando un individuo se convierte en un asesor del gabinete en turno. En el festival también actuó Kawazoe Makoto, dirigente del Sindicato de Trabajadores de Envío [haken] del Área Metropolitana 首都圈派遣ユニオン. Hubo conferencias del periodista Kamata Satoshi y el fotorreportero Moriguchi Katsu, conocido por sus obras sobre Okinawa. El abogado Utsunimiya Kenji, presidente de la Red contra la Pobreza, saludó, y la presidenta del Partido Socialdemócrata, Fukushima Mizuho, pidió permiso para hablar sobre las actividades en pro de las víctimas del accidente nuclear de Fukushima. La tocada que ocupó la segunda mitad del programa estuvo a cargo del DJ Freedom School Crew y de JariBu Afrobeat Arkestra, quienes donaron la función para la causa. Entre el costo de la entrada, un libro de Yuasa que estaba en venta, un té y un curry vegetariano, aporté 2660 yenes. Había alrededor de 120 asistentes. Este tipo de actividades se llevan a cabo regularmente para recabar fondos para Moyai y la Red contra la Pobreza. 


\section{Conclusión}

La crisis que vive Japón es crisis del neoliberalismo, del capitalismo global que impuso su lógica de acumulación y profundizó la explotación mediante la recreación de la pobreza entre los empleados de mayor edad por despido masivo en una primera etapa, y entre los jóvenes mediante la política de diferenciación por la escolaridad y la calidad educativa, además del género y la etnia, que siguen operando desde hace por lo menos más de ciento veinte años en el país. Según teóricos y políticos neoliberales, la diferenciación es necesaria para estimular a los individuos a mejorar económicamente; sin embargo, ha producido pobreza, de la cual difícilmente puede escaparse. Opera un mecanismo que retiene a los pobres en la pobreza y reproduce la pobreza si no se modifica la política radicalmente. La crisis neoliberal afecta a casi un tercio de la población juvenil y amenaza la viabilidad futura de Japón como una sociedad estable con decoroso nivel de vida. Si no hay jóvenes con empleo estable, en condiciones decorosas, colapsará el sistema de seguridad social, y no habrá mujeres jóvenes que deseen procrear hijos sin la garantía de un ingreso suficiente para su salud y su educación. En las condiciones de una sociedad civil casi disuelta y con debilitados políticos alternativos que compartan su sentir y modo de expresar, los jóvenes toman la calle y ensayan nuevos medios de comunicación para convocar, actuar y responder a las necesidades concretas; así, acumulan experiencia y construyen una nueva cultura política.

La crisis del neoliberalismo japonés es similar a la que experimenta gran parte de la humanidad. Encima, el país afronta serios problemas para controlar el desastre nuclear, además de los gastos por la reconstrucción, lo que acrecienta la de por sí enorme deuda pública interna. El gobierno de Abe propone una salida de la crisis mediante el desarrollo económico en las industrias de alta tecnología, incluidas las de armamento, ${ }^{48}$ la expansión del sistema de servicios personales, y la exportación de obras de infraestructura, incluidas plantas nucleoeléctricas, a los países en vías de desarrollo; es la conocida fórmula de "Haz

${ }^{48}$ A principios de 2013 se promovió y se aprobó en la Dieta el proyecto para anular de la prohibición de producción y exportación de armamento. 
una gran torta (crecimiento industrial), y así te tocará un gran pedazo (ingreso familiar)". En contraste, algunos ciudadanos jóvenes de la "generación perdida" han señalado el carácter estructural de la pobreza juvenil, que el crecimiento industrial no conduce por sí mismo al bienestar de la población en general, $\mathrm{y}$ adoptaron iniciativas para solucionar la pobreza estructural mediante acciones solidarias abiertas a la colaboración con otras propuestas gubernamentales o privadas. ¿Qué postura asumirán otros ciudadanos de la "generación perdida", en particular, su ala neonacionalista? El papel de Japón en el futuro como parte de la humanidad dependerá de qué lecciones saque y en qué acciones las transforme esta generación de japoneses, en especial, los jóvenes con la experiencia del desastre y de la solidaridad humana.

Dirección institucional de la autora:

Centro de Estudios de Asia y África

El Colegio de México

Camino al Ajusco 20

Pedregal de Santa Teresa

10740, México, D.F.

tanaka@colmex.mx

\section{Bibliografía}

Akagi, Tomohiro, "Mruyama Masaono hoppetao hippatakitai", Ronza, enero de 2007.

Asahi shinbunsha "Rosutozenerēshon" shuzaihan, Rosutozenerēshon, Tokio, Asahishinbunsha, 2007.

Fuкumoto, Emi et al., "Jiyūto seizonno Mēdē 2010. Demotaiga

Shinjukuno hankagaiwo neriaruku", comunicado electrónico, Japan Alternative News for Justices and New Cultures Blog, 5 de mayo de 2010. [janjanblog.com/archives1340, consultado el 18 de junio de 2010.]

Gendai nōgyō, número especial: Datsugurobarizeshon, 2007. Hatoyama, Yukio, “A New Path for Japan”, The New York Times, 26 de agosto de 2009.

IwatA, Masami, Gendai no binkon. Working poor/homeless/seikatsuhogo, Tokio, Chikumashobō, 2007. 
Jo, Shigeyuki, Sannendeyametawakamonorwa dokoeittanoka. Autosaidāno jidai, Tokio, Chikumashobō, 2008.

Kanda, Fumihito, Shōwa Heizei gendaishi nenpyō, Tokio, Shōgakkan, 2005.

Katō, Tetsurō, Jōhōsen no jidai. Internet to gekijōseiji, Tokio, Kadensha, 2007.

Keizai Dantai RengōKai, Propuesta para la formación de la generación que debe sobrevivir el siglo XXI. Promover más reformas con base en la "pluralidad", la "competencia" y la "evaluación", Tokio, Keizai Dantai Rengōkai, abril de 2004.

Kobayashi, Yoshinori, Sensōron, Tokio, Gentōsha, 1998.

KōSEISHŌ, "Sōtaiteki hinkonritsu", octubre de 2009. [www.mhlw. go.jp/houdou/2009/10/dl/h1020, consultado el 1 de diciembre de 2015.]

Kosugi, Reiko, Jiyūnodaishō/Freeter, Tokio, Rōdōseisaku Kenkyūkenshūkikō, 2002.

Kosugr, Reiko, "Youth Employment in Japan's Economic Recovery:

'Freeters' and 'NEETs'", Japan Focus: The Asia Pacific Journal, 11 de mayo de 2009. [www.japanfocus.org/-kosugi-reiko/2022/ articles.html, consultado el 7 de diciembre de 2015.]

Oficina del Primer Ministro, Jyakunen koyōwo torimaku genjō to mondai, 19 de marzo de 2012. [kantei.go.jp/jp/singi/koyoutaiwa /dai7/shiryu1.pdf, consultado el 19 de marzo de 2012.]

Ozawa, Ichirō, Nihon kaizō keikaku, Tokio, Kōdansha, 1993. Tachibanaki, Toshiaki, Nibonnno keizaikakusa, Tokio, Iwanami, 1998.

Tanaka, Michiko, Cambios políticos en Japón en 1993, México, UNAM, 1993.

TANaka, Michiko (coord.), Política y pensamiento político en Japón, 1926-2012, México, El Colegio de México, 2014.

Wikipedia (en japonés), "Yuasa, Makoto". [Ja.wikipedia.org/wiki/ 湯浅誠, consultado el 27 de noviembre de 2015.]

YuASA, Makoto, Hanbinkon. Suberidaishakaikarano dasshutsu, Tokio, Iwanamishoten, 2008.

YuAsA, Makoto, Hinkon shürai. Hinkonwa jikosekininjyanai, Tokio, Yamabukishoten, 2007.

YuASA, Makoto, "Seismic Disaster and Poverty in Japan: Everyday-life Support to Victims and Community Organization", ponencia presentada en el simposio internacional Desastre de Fukushima y futuro de la energía nuclear, XII Congreso Internacional de la Asociación Latinoamericana de Estudios de Asia y África, Puebla, junio de 2012. 
